\title{
WORLD JOURNAL OF CURRENT MEDICAL AND PHARMACEUTICAL RESEARCH
}

\author{
www.wjcmpr.com ISSN: 2582-0222
}

\begin{abstract}
A Review on Pharmacological Activities of Alkaloids
Badri.Sireesha1*, Basu Venkateswara Reddy², S.Khadar Basha ${ }^{3}$, K.Chandra ${ }^{3}$, D.Anasuya ${ }^{3}$, M.Bhavani ${ }^{3}$.

${ }^{*}$ Assistant professor, Sankar Reddy Institute of Pharmaceutical Sciences, Salakalaveedu(V), Bestavaripeta (M), Prakasam (D), Pincode523370.

2Professor, Sankar Reddy Institute of Pharmaceutical Sciences, Salakalaveedu(V), Bestavaripeta (M), Prakasam (D), Pincode-523370. 3B.Pharmacy, Sankar Reddy Institute of Pharmaceutical Sciences, Salakalaveedu(V), Bestavaripeta (M), Prakasam (D), Pincode-523370.

ABSTRACT

Alkaloids are a category of molecules in nature around the globe with a relatively large occurrence. These are chemicals and biomolecules that are very complex. Alkaloids are compounds of a very diverse class of secondary plant metabolites; alkaloids, such as anticholinergic, antitumor, diuretic, antiviral, antihypertensive, antiulcer, analgesic, and anti-inflammatory, have been linked to extensive list of biological activities. The basic character of alkaloids allows salts to be formed with mineral acids or organic acids, alkaloid salts are usually soluble in water and dilute alcohols, and are not soluble in organic solvents except in rare cases. This research is carried out mainly in the context and classification of alkaloids and alkaloids pharmacological practices.
\end{abstract}

Key words:

Alkaloid, Secondary metabolites, Pharmacological activity, Organic acids, Analgesic.

\section{Article History:}

Received On: 30.09.2019,

Revised On: 25.12.2019,

Accepted On: 27.12.2.19.

\section{*Corresponding Author}

Name: Badri.Sireesha

Email: sireeshasiri1282@gmail.com http://doi.org/10.37022/WJCMPR.2019.01068

\section{INTRODUCTION}

Phytochemistry deals with plant chemical components, structure of phytochemicals, and their biosynthesis and biological activities. Phytochemicals referred to as plant components that are biologically active. The constituents of the plant have been graded into primary and secondary metabolites. Sugar, amino acids, nucleic acid, etc. are the main metabolites. Thus alkaloids, anthocyanin, flavonoids, terpenoids, etc. were secondary. Such metabolites differ in quantity from species to species. The Alkaloids were the largest group of secondary metabolites present in the living organism. Alkaloids rarely existed on their own, they were a combination of a few major alkaloids and a few minor ones.It has various structure types, properties and pharmacological activities. Most alkaloids contain negative oxidation nitrogen and sulphur, oxygen and phosphorus in addition to carbon, hydrogen ${ }^{1}$.

Alkaloids are a group of naturally occurring chemical compounds that contain most of the basic atoms of nitrogen. There are also some related compounds with neutral and even weakly acidic properties in this group. Alkaloids are also attributed to some synthetic compounds of similar structure. In addition to carbon, hydrogen and nitrogen, alkaloid molecules may contain sulfur and rarely chlorine, bromine or phosphorus. Alkaloids are formed by a wide range of species, including bacteria, fungi, plants and animals, and are part of a group of natural products (also known as secondary metabolites).

A highly diverse category of chemical entities are plant alkaloids, one of the largest groups of natural products. Alkaloids include a huge class of around 12,000 natural products. The main requirement for classification as an alkaloid is the presence at any position in the molecule of a simple nitrogen atom that does not contain nitrogen in an amide or peptide bond. The alkaloids form a group of structurally diverse and biogenically unrelated molecules, as suggested by this extraordinarily broad definition. Many of these compounds have powerful effects on pharmacology ${ }^{2}$.The well-known plant alkaloids, for example, include narcotic analgesics, morphine and codeine, apomorphine (a morphine derivative) used in Parkinson's disease, muscle relaxant papaverine, and sanguinarine and berberine antimicrobial agents. A number of potent anti-cancer drugs from plant compounds have also been produced.

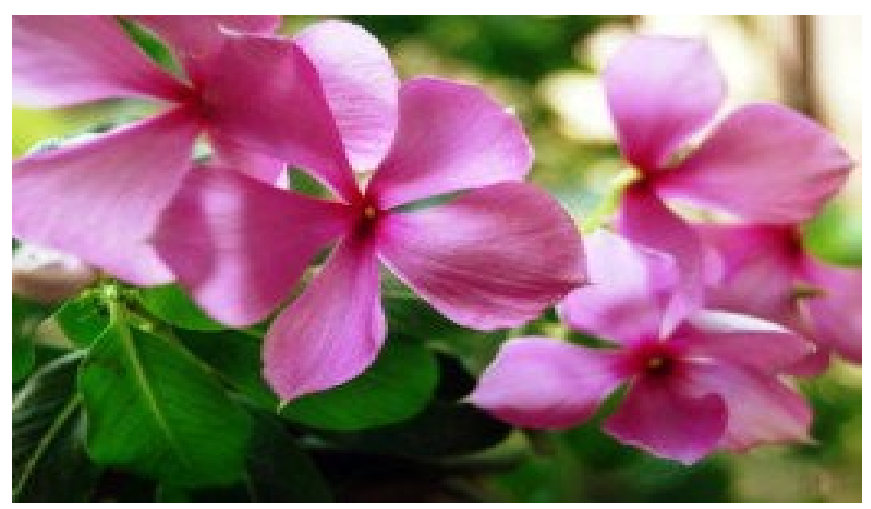

Fig 1: Secondary metabolic alkaloids

\section{HISTORY}

Alkaloid-containing plants have been used for medicinal and recreational purposes by humans since ancient times. For instance, in Mesopotamia, medicinal plants were known at least around 2000 BC. Homer's Odyssey referred to a gift given by the Egyptian queen to Helen, a substance that leads to oblivion. The gift is thought to have been an opium-containing drug. A Chinese houseplant book written in I-III centuries BC described a medicinal use of Ephedra and opium poppies. Coca leaves have also been used since ancient times by South American Indians. Extracts from plants that contain toxic 
alkaloids, such as aconitine and tubocurarine, have been used to poison arrows since antiquity ${ }^{3}$.

Alkaloid studies started in the 19th century. In 1804, in memory of Morpheus, the Greek god of dreams (the modern name "morphine" was given by the French physicist Joseph Louis Gay-Lussac), the German chemist Friedrich Serturner extracted from opium a "soporific theory" (Latin: principiumsomniferum). The French researchers Pierre Joseph Pelletier and Joseph Bienaime Caventou, who discovered quinine (1820) and strychnine (1818), made a significant contribution to the chemistry of alkaloids in the early years of their growth. Several other alkaloids were discovered around that time, including xanthine (1817), atropine (1819), caffeine (1820), coniine (1827), nicotine (1827), colchicine (1833), sparteine (1851) and cocaine(1860).

In 1886, the German chemist Albert Ladenburg performed the first complete synthesis of an alkaloid. By reacting with acetaldehyde to 2-methylpyridine and reducing the resulting 2propenyl pyridine with sodium, he developed coniine. The development of alkaloid chemistry has been driven in the 20th century by the advent of spectroscopic and chromatographic methods and more than 12,000 alkaloids have been identified by $2008^{4}$.

\section{GENERAL CHARACTERISTICS OF ALKALOIDS}

Most of the alkaloids are bitter taste, weak foundation, colorless, poorly water-soluble and readily soluble in organic solvents such as diethyl ether, chloroform, etc., some alkaloids are colored as Berberine is yellow color and Sanguinarine's salt is red copper color. Save for strychnine and caffeine ${ }^{5}$, the alkaloids should be heat-decomposed. Mostly crystalline solids are the physical form of alkaloids, and few are amorphous solids.

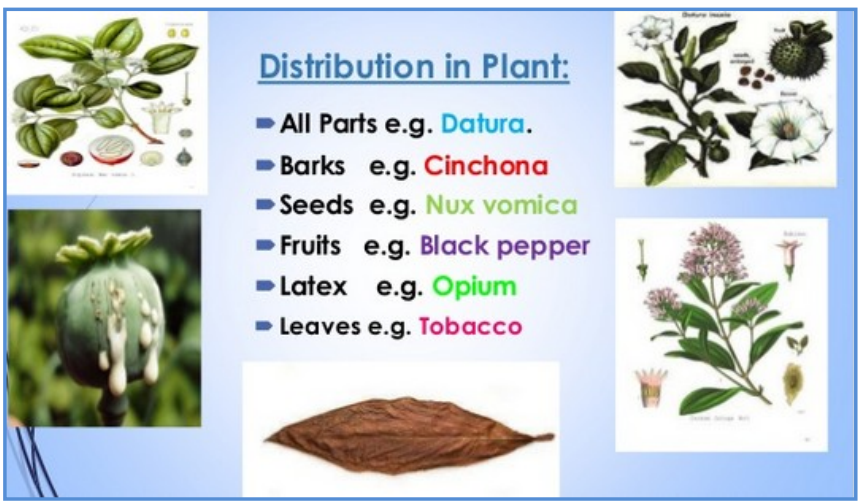

Fig 2: Distribution of alkaloids from various plants

Alkaloids are produced by different living organisms; in particular by higher plants-about 10 to 25 percent of those contain alkaloids. Hence, the word "alkaloid" has been associated with plants in the past. The content of alkaloids in plants is usually within a few percentage points and is inhomogenous across the tissues of plants. Depending on the type of plants, the maximum concentration is observed in the leaves (black henbane), fruits or seeds (Strychnine tree), root (Rauwolfia serpentina) or bark (cinchona).In addition to plants, alkaloids are present in some forms of fungi, such as aspsilocybin in the Psilocybe genus mushroom, and in animals, such as bufotenin in some toads ' fur. There are also alkaloids in many marine organisms. Many amines, such as adrenaline and serotonin, which play an important role in higher animals, in their structure and biosynthesis are similar to alkaloids and are sometimes called alkaloids ${ }^{6}$.

\section{CLASSIFICATION OF ALKALOIDS:}

There is no standard structure classification for alkaloids relative to other types of naturally occurring conpounds. Present-day classified alkaloids based on the carbon skeleton in the alkaloids.

\section{TYPES OF ALKALOIDS}

\section{True alkaloids:}

It contains heterocyclic ring with nitrogenand origenated from amino acids.

Ex: Atropine, Nicotine,Morphine

Proto alkaloids:

No heterocyclic ring with Nitrogen and derived from amino acids.

Ex:Ephedrine,Mescaline,Adrenaline

Pseudo alkaloids:

Contains heterocyclic ring with Nitrogen but not derived from amino acids.

Ex: Caffeine, Theobromine, Theophylline

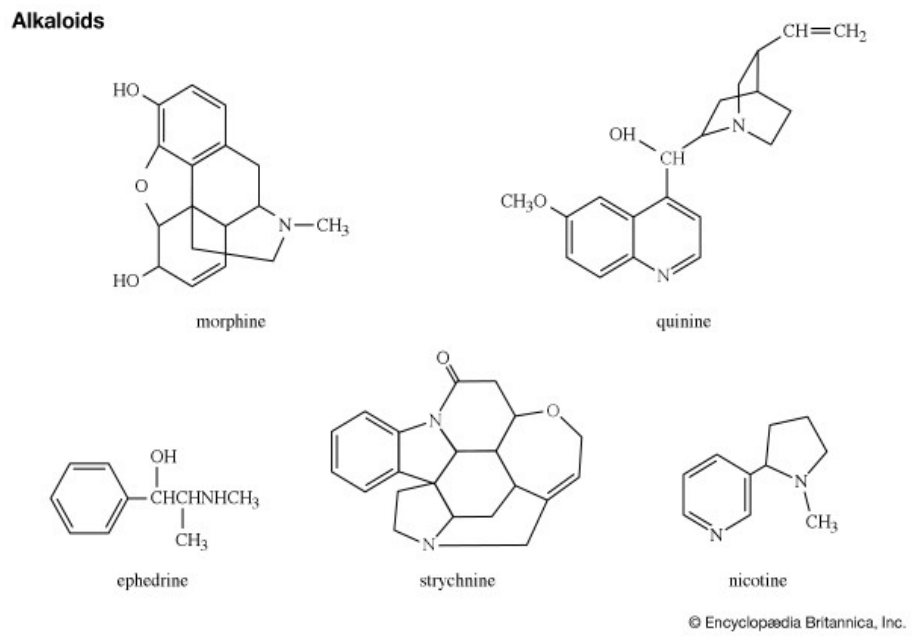

Fig 3: Structures of different class alkaloids

Table 1: Classification of alkaloids

\begin{tabular}{|c|c|c|c|}
\hline $\begin{array}{l}\text { Biosyntheti } \\
\text { c } \\
\text { Classificati } \\
\text { on }\end{array}$ & $\begin{array}{c}\text { Chemical } \\
\text { classificatio } \\
\text { n }\end{array}$ & $\begin{array}{l}\text { Pharmacological } \\
\text { classification }\end{array}$ & $\begin{array}{c}\text { Taxonomic } \\
\text { classification }\end{array}$ \\
\hline Indole & Tropane & Morphine & $\begin{array}{c}\text { Cannabinaceou } \\
\mathrm{s}\end{array}$ \\
\hline Piperidine & Quinoline & Quinine & Rubiaceous \\
\hline Pyrrolidine & Purine & Lobeline & Solanaceous \\
\hline $\begin{array}{l}\text { Phenylethyl } \\
\text { amine }\end{array}$ & Diterpine & Aconitine & - \\
\hline Imidazole & Steroidal & Ergonovine & - \\
\hline
\end{tabular}


Table 2: Chemical classification of alkaloids

\begin{tabular}{|c|c|}
\hline \multicolumn{2}{|c|}{ Based on chemical structure } \\
\hline Heterocyclic & Non-heterocyclic Alkaloids \\
\hline Pyrrole & N-Methyltramine \\
\hline Pyrrolidine & Ephedrine \\
\hline Pyridine & Pachysandrine \\
\hline Tropane & Mescaline \\
\hline Quidine - Quinoline & Erythromycin \\
\hline Isoquinoline & Colchicine \\
\hline Aporphine & Jurubin \\
\hline Purine & Taxol \\
\hline Indole & - \\
\hline Terpenoid & - \\
\hline
\end{tabular}

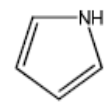

pyrrole

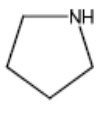

pyrnolidine<smiles>C1CCNCC1</smiles>

piperidine<smiles>c1ncc2[nH]cnc2n1</smiles>

purine<smiles>CN1C2CCCC1CC2</smiles>

tropane<smiles>O=c1ccc2ccccc2[nH]1</smiles>

Quinolone<smiles>c1ccc2[nH]ccc2c1</smiles>

Indole

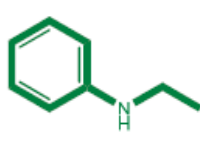

Phenyl ethyl amine
Ephedrine

Hordenine

Fig 3: Examples for Heterocyclic alkaloids

\section{DISTRIBUTION AND LOCALIZATION OF ALKALOIDS}

Alkaloids have a complex structure, initially characterized as nitrogen-containing, basic substances of natural origin and restricted distribution. Their nitrogen atom is part of a heterocyclic system and they have significant pharmacological activity; they occur only in the vegetable kingdom, according to some authors. They are known as salts, and we can add that they are formed from an amino acid biosynthetically. Such elements describe what might be called true alkaloids. In addition, several scholars differentiate protoalkaloids and pseudoalkaloids ${ }^{8}$.Only seldom do alkaloid-containing plants contain only one alkaloid: often they contain essentially one component (hyoscyamine from belladonna's leaves), but most often they create a complex mixture that can be dominated by one major component. Having several hundred alkaloids in one medication is not unusual. As a general rule, all of a given plant's alkaloids have a similar biogenetic origin, even though their structures may seem very different at first. The concentration of alkaloids in a given plant can vary widely from part to part, and there may be none in some parts.

\section{PROPERTIES OF ALKALOIDS}

The only character that probably distinguishes all alkaloids is that they have nitrogen. This nitrogen is generally derived from amino acid, incorporated into a heterocyclic ring, and is fundamental. Pelletier (1983) described an alkaloid as a cyclic compound in a negative oxidation state containing nitrogen that has a limited distribution among living organisms. Alkaloids have physiological activity in animals almost always, although some of them have minimal effects. The majority of alkaloids are well-defined crystalline substances that combine to form salts with acids. They can exist as salts or as $\mathrm{N}$-oxides in the plant in the Free State. Many alkaloids contain oxygen in addition to the carbon, hydrogen and nitrogen elements. Others, like hemlock coniine and tobacco nicotine, are oxygenfree and liquid. Although colored alkaloids are relatively rare, they are not unknown; for example, berberine is yellow, and copper-red is the sanguinarine salts 9 .

The basic character of alkaloids allows mineral acids (hydrochlorides, sulfates, nitrates) or organic acids (tartrates, sulfamates, and maleates) to form salts. In general, alkaloids salts are soluble in water and distilled alcohols and are not soluble in organic solvents except in rare cases. The crystallized salts can be relatively well preserved, and these compounds are the can commercial type.It is of great medicinal significance to understand the solubility of alkaloids and their salts. Alkaloidal substances are not only commonly administered in solution, but the insolubility differences between alkaloids and their salts also provide methods for isolating alkaloids from the plant and distinguishing them from non-alkaloidal substances.

\section{PHARMACOLOGICAL ACTIVITIES OF ALKALOIDS}

Alkaloids are used for a number of biological activities, each of which has its own specific action mechanism. Most of these processes were confirmed, but some were speculated. Here we are addressing the alkaloids ' essential biological activities.

\section{MUSCLE RELAXANT}

It is understood that alkaloids have a relaxing muscle effect. Dtubocurarine is one such example of anti-paralytic activity due to its ability to block the spots of the acetycholine receptor that helps the muscles to relax at neuromuscular intersections. Mahonia aquifolium-isolated aporphine alkaloids including corstubenne, magnoflorine, isothebaine, and isocorydine were reported to relax the contractions induced by nor-adernaline compared to those induced by $\mathrm{KCl}$ in isolated rat aorta ${ }^{10}$.

\section{ANTIOXIDANT PROPERTY}

Alkaloids are known to have antioxidant activities because of their ability to act as free radical scavengers, metal chelating activity, or the ability to contribute electron or hydrogen. A quinoline alkaloid derived from Oryza sativa cv's aleurone base. It has strong antioxidant properties using radical substrate 2,2-diphenyl-1-picrylhydrazyl (DPPH). Indoles and their analogs against radical cations 2,2'-azino-bis(3ethylbenzothiazoline-6-sulphonic acid) (ABTS) produce higher physiological $\mathrm{pH}$ radical scavenging activity.The norditerpene alkaloids, including linearilobin, linearilin, lycotonin browniine, isolated from the roots of Delphinium linearilobum (Trautv.), exhibited antioxidant activity using DPPH and metal chelating assays $^{11}$. Pyrrole alkaloid isolated from Arum palaestinum Boiss, while it also exhibits antioxidant and cytotoxic effects of alkaloids such as berberine, canadine, anonaine and antioquine in the same way as alpha tocopherol and trolox have been found. 


\section{ANTICANCER ACTIVITY}

Catharanthus roseus (Apocynaceae) vinblastine and vincristine alkaloids are popularly used to treat patients with leukemia and hodgkin disease. These alkaloids exert chemopreventive effect by ending or causing the protein microtubules that form the mitotic spindle in the cell division to be depolymerised. It impedes the division and differentiation of tumor cells and reduces cancer incidences. Divalent calcium cation $(\mathrm{Ca} 2+)$, by acting as a major signaling molecule during cell signal transduction, is known to control energy output and cellular metabolism.Benzyisoquinoline alkaloids are reported to act as lipid peroxidation inhibitors induced by $\mathrm{Fe} 2+$ /cysteine in rat liver microsomal fractions due to the presence of phenolic hydroxyls or similar reactive classes. Martefragin A-an indole alkaloid isolated from the red algae Martensia fragilis has been reported to show inhibitory activity in rat liver microsomes for NADPH-dependent lipid peroxidation ${ }^{12}$.

\section{ANTIMICROBIAL AND AMOEBICIDAL ACTIVITY}

The phenanthridine-like alkaloids derived from Chelidonium majus Linn. Imidazole derivatives with tremendous therapeutic potential and also developed antibacterial activity. It was also found that imidazole moiety compounds act as inhibitors of p38 MAP Kinase and 5-Lipoxygenase. In addition to the cytotoxic potential associated with these alkaloids, bisbenzylisoquinoline alkaloids such as cycleanine and cocsoline isolated from Albertisia villosa have antibacterial, antifungal, antiplasmodial capacity.Isolated from Delphinium spp. Diterpenoid alkaloids. Moderate antifungal activity was reported, along with antifeed activity against the Spodoptera littoralis and Leptinotarsa decemlineata insect species. Eudistomin, a novel oxathiazepine ring that contains alkaloids isolated from Eudistoma olivaceum against RNA viruses such as CoxsachieA-21 and equine rhinovirus, and against DNA viruses such as HSV-1, HSV-2, Vaccinia virus has been mentioned by indole alkaloids ${ }^{12,13}$.

It has been documented that the quinoline alkaloids including skimmianine, kokisaginine and male isolated from Raulinoa echinata demonstrate antifungal activity against Leucoagaricus gongylophorus, the symbiotic fungus of leaf cuttings ants (Atta sexdens) and in vitro against Trypanosoma cruzi species. Wirasathien et al. demonstrated that antituberculosis activity against Mycobacterium tuberculosis, antimalarial activity against Plasmodium falciparum and cytotoxic activity against epidermoid carcinoma (KB), breast cancer (BC) and small cell lung cancer (NCI-H187) cell line are reported to occur with aporphine alkaloids extracted from the aerial portion of Pseuduvaria setosa ${ }^{14}$.

\section{OTHER ACTIVITIES}

Alkaloid activity against herbivores, vertebrate toxicity, cytotoxicity activity, alkaloid molecular targets, mutagenic or carcinogenic activity, antibacterial, antifungal and antiviral properties, and their possible functions as phytoalexins were tabulated. Most alkaloids are dangerous enough for animals if they are ingested to cause death. Several alkaloids are used as insecticides, such as nicotine andanabasine. Many alkaloids, one of two important animal information systems, act on the nervous system.It is reported that plants containing protoberberine alkaloids are used in Chinese folk medicine as analgesics, antiseptics, sedatives, and stomatics. Such plants are used in Indian and Islamic folk medicine for bleeding and eye diseases, as well as antiseptics, sedatives, stomatics, and depressants of the uterine muscle. Both quaternary alkaloids and their tetrahydro derivatives have been reported to have many substantiated biological and therapeutic effects, such as palmatine, jatrorrihizine, and tetrahydropalmatine. Tetrahydropalmatine is used as an analgesic in China, and bradycardial, hypotensive, and sedative activities have been reported to be present ${ }^{15}$.

\section{CONCLUSION}

The present analysis concluded that with examples was explained the past and origin of alkaloids, the actual distribution of alkaloids, forms and different classes of alkaloids. Alkaloids are derived from different plants. Depending on the different chemical moods, these are categorized into different classes such as indole alkaloids, tropane alkaloids, quionoline alkaloids, pyrrole alkaloids and piperidine alkaloids etc. Alkaloids often show several pharmacological behaviors such as anticancer, carcinogenic, anti-microbial, cytotoxic and vasospastic activities.

\section{REFERENCES}

1. J.-X. Zhang, Z.-R. Yang, D. Suppressive effect ofsinomenine combined with 5-fluorouracil on colon carcinomacell growth. Asian Pacific Journal of Cancer Prevention 2014; 15(16): 6737-6743.

2. Michael Wink. Functions and biotechnology of plant secontary metabolites. Introduction, Chapter 1. Ann Plant Rev 2010;39:1-20.

3. Michael Wink. Biochemistry, physiology and ecological function of secondary metabolites. Chapter 1, Introduction. Wiley-Blackwell Ann Plant Rev b(40): 1-19.2010.

4. Kaisa A Salminen, Achim Meyer, Lenka Jerabkova. Inhibition of human drug metabolizing cytochrome P450 enzymes by plant isoquinoline alkaloids. Phytomedecine 2011; 18:533-538.

5. Sarah O'Connor. Alkaloids in comprehensive natural products IIL. Mander, H-W. Lui, Eds. Elsevier. Oxford 2010; 1: 977-1007.

6. Jean Bruneton. Pharmacognosy, phytochemistry, medicinal plants. Lavoisier, 2nd Edition; 1136.1999.

7. Noureddine Bribi, Messaoud Belmouhoub, Fadila Maiza. Analgesic and anti-inflammatory activities of ethanolic extract of fumaria capreolata. Phytothérapie 2017; 15(4): 211-216.

8. Maria Contreras, Noureddine Bribi, Anna GomezCaravaca. Alkaloids profiling of fumaria capreolata by analytical platforms based on the hyphenation of gas chromatography and liquid chromatography with quadrupole-time-of-flight mass spectrometry. Int J of Anal Chem 2017; 5: 1-16.

9. Ma Weina, Zhu Man, Zhang Dongdong. Berberine inhibits the proliferation and migration of breast cancer ZR-75-30 cells by targeting Ephrin-B2. Phytomedicine 2017; 25: 45-51.

10. Feng Zuo, Norio Nakamura, Teruaki Akao. Pharmacokinetics of berberine and its main metabolites in conventional and pseudo germ-free rats determined by liquid chromatography/ion trap mass spectrometry. Drug Metab Dispos 2006;34:2064-2072.

11. C.-W. Yang, W.-L. Chen, P.-L. Wu, H.-Y. Tseng, and S.-J. Lee. Anti-inflammatory mechanisms of 
phenanthroindolizidine alkaloids. Molecular Pharmacology 2006; 69(3): 749-758.

12. C. R. Pradeep and G. Kuttan. Piperine is a potent inhibitor ofnuclear factor $-\kappa \mathrm{B}$ (NF- $\kappa \mathrm{B})$, c-Fos, CREB,ATF-2 and proinflammatorycytokine gene expression in B16F-10 melanoma cells. Int Immunopharmacol 2004; 4(14): 1795-1803.

13. M. E. Matheus, F. D. A. Violante, S. J. Garden, A. C. Pinto,and P. D. Fernandes. Isatins inhibit cyclooxygenase-2 andinducible nitric oxide synthase in a mouse macrophage cellline. Eur J of Pharmacol 2007; 556: 200-206.

14. Z. Zhao, J. Xiao, J. Wang, W. Dong, Z. Peng, and D. An. Anti-inflammatory effects of novel sinomenine derivatives. Int Immunopharmacol 2015; 29(2): 354360.

15. D.-P. Chen, C.-K.Wong, P.-C. Leung. Antiinflammatoryactivities of Chinese herbal medicine sinomenine and LiangMiao San on tumor necrosis factor- $\alpha$-activated humanfibroblast-like synoviocytes in rheumatoid arthritis. J of Ethnopharmacol 2011;137(1): 457-468.

16. Q. Wang and X.-K. Li. Immunosuppressive and antiinflammatoryactivities of sinomenine. Int Immunopharmacol 2011; 11(3): 373-376.

17. Q. Li, W. Zhai, Q. Jiang. Curcumin-piperine mixtures inself-microemulsifying drug delivery system for ulcerative colitistherapy. Int J of Pharmaceutics 2015; 490(1-2): 22-31.

18. V. Yadav, F. Varum, R.Bravo, E.Furrer, D. Bojic, and A.W.Basit. Inflammatory bowel disease: exploring gut pathophysiologyfor novel therapeutic targets. Translational Research 2016; 176: 38-68. 